\title{
ARTIGOS
}

\section{INFLUÊNCIA DA CIVILIZAÇÃO EGÍPCIA SÔBRE A OBRA DE MOISÉS}

No século passado, alguns filósofos e historiadores de reconhecido valor, procurando apreciar com espirito positivo a personalidade e a obra de Moisés, foram levados a concluir que a velha cultura religiosa e moral dos egipcios tinha sido a principal fonte inspiradora do grande chefe hebreu, tanto na fundaçāo de seu monoteismo, como na sintese dos sábios preceitos do Decálogo.

Realmente, pondo-se de parte a explicaçāo teológica, nāo seria possivel acreditar que concepções tão elevadas, resultantes de análises tāo profundas, pudessem ter surgido espontâneamente entre os israelitas, numa época em que ainda eram simples pastores nômades e em que se mostravam dominados pelo espirito fetichista. Seria anti-filosófico.

Por outro lado, a tradiçāo bíblica robustecia, de certo modo, a hipótese da influência egípcia, e os próprios nomes de Moisés, Pinhas, Hur e Hofni reforçavam a idéia, porque, efetivamente, mais parecem de origem nilótica do que israelita. $\mathrm{Na}$ época, por conseguinte, a mencionada hipótese era a melhor possivel.

Hoje, entretanto, já seria difícil sustentar êste ponto de vista, sem dúvida muito interessante. Os estudos progrediram. A análise minuciosa dos monumenos e das antigas obras, inclusive das diferentes versões da Bíblia, e os comentários críticos realizados nestas últimas décadas trouxeram esclarecimentos que nāo mais permitem certas conclusões fantasistas. Os conceitos modernos impõem-se, aliás, pela simplicidade.

Em primeiro lugar, cumpre ter em vista que nem a permanência dos hebreus no vale do Nilo, nem o célebre êxodo, podem ser confirmados, mesmo de maneira superficial, por qualquer documento estranho a Israel. Neste particular, os monumentos egipcios, pelo menos até agora, têm-se mantido no mais absoluto mutismo.

Em tal circunstância, e num louvável esfôrço de explicaçāo para as tradições biblicas, Winckler, entre outros, formulou uma hipótese muito engenhosa, que se pode resumir da seguinte maneira: Primitivamente, com o nome de Misraim, compreendia-se, nāo só - Egito, mas tôda a regiāo também chamada Misr ou Musri, vale dizer, o norte da Arábia, regiāo a que pertencia parte do vale do Nilo, aos olhos dos habitantes da Ásia. Quando, pois, mais tarde, os hebreus falavam na permanência dos antepassados em Misraim, tinham em vista os desertos ao sul da Palestina, e nāo pròpria- 
mente o Egito. Existem, de resto, alguns dados históricos insuspeitos, que, de certo modo, consolidam estas idéias.

A hipótese de Winckler (já que estamos no terreno das hipóteses) pode ser rematada pela de Hugo Gressmann, que traçou a marcha conjetural dos hebreus, de maneira muito hábil. Um pequeno grupo de nômades, desta raça, obteve autorizaçāo para se fixar nas fronteiras do Egito, numa. regiāo de pastagens, entre o delta e o deserto da Arábia. Viria tangido pela fome, pela sêde, ou, talvez, como diz a história de José, por "seus irmāos", que, neste caso, seriam outras tribos mais fortes de beduinos.

As penetrações temporárias de povos pastores, nas fronteiras asiáticas do Egito, sempre foram admitidas pelos faraós, e num documento antiquíssimo, da nona ou da décima dinastia (2360-2160), há referência a nômades que "tentaram descer ao Egito para pedir água, segundo o seu costume, e para dar de beber a seus rebanhos". Aliás, não faltam exemplos de casos semelhantes a êste.

Falsa é, porém, a moderna tradiçāo bíblica, que supõe os hebreus dispersos entre os egípcios, vivendo como felás, ou instalados na própria capital. Não șó por motivos religiosos, mas ainda por se tratar de criadores de cabras e ovelhas, é claro que êstes estrangeiros tinham necessàriamente de permanecer em lugares onde houvesse pastagens; nāo no vale do Nilo, mas num território a parte, chamado país de Gochen, ou Gessen. As tradições de Israel colocavam o seu habitat primitivo na regiāo de Tanis e $\mathrm{Pe}$ lusa, mas é provável que o uádi Tumilat, habitado, na época, por beduinos, também fizesse parte do país de Gessen, embora nāo totalmente.

Nesta regiāo, ou nas circunvizinhanças, haviam os faraós da XVIII dinastia construido duas praças fortes para a defesa do Egito. Chamavam-se Pitom e Ramsés.

Quanto a esta última cidade - a que os gregos deram o nome de Pelusa - mais tarde Ramsés I, Seti I (1321-1300) e Ramsés II (1300-1234) a melhoraram e ampliaram consideràvelmente. Ramsés II deu-lhe mesmo extraordinário desenvolvimento, transformando-a numa brilhante capital, onde por vêzes residia, utilizando-a como base de abastecimentos para as suas campanhas na Ásia.

Ao que se pode deduzir, foi por esta época que um dos aludidos faraós, talvez Ramsés II, resolveu aproveitar os pastores hebreus como operários, para reconstruir as muralhas, os armazens e. os templos das duas praças.

Tornou-se Moisés, desde logo, a alma da resistência israelita à opressāo egipcia, resistência tenacissima, pois era a revolta da ociosidade de nômades contra o trabalho forçado... Seria preferivel voltar para o deserto, onde nāo encontrariam nem água, nem alimento! 
$E$, apesar das imensas dificuldades, evadiram-se os hebreus para as estepes, que se estendem ao sul da Palestina, e nestas estepes permaneceram, miseràvelmente, durante quarenta, ou cin.qüenta anos, segundo a tradiçāo biblica...

Que se sabe de verdadeiro a respeito de Moisés, desde entāo, chefe e guia dos hebreus? Infelizmente, nāo há documentos contemporâneos, capazes de assegurar-nos, de modo positivo, quem êle foi e o que precisamente empreendeu. Nenhum elemento do Pentateuco pode ter sido, de fato, redigido durante sua existência. Entre a época de Moisés e a épóca da redação dos mais antigos documentos, que dêle nos falam, houve um espaço de cinco ou seis séculos. Hoje, esta é noçāo inteiramente pacífica, entre os historiadores.

Já, porém, bem longe vai o tempo em que o desvairamento metafísico pretendia transformar os mais célebres heróis e gênios da Antiguidade em meros sêres mitológicos. Não! Moisés existiu e foi, sem dủvida, um dêsses raros homens, uma dessas individualidades excepcionais que, no passado, deram impulso decisivo à vida politica e religiosa dos povos.

Antes de Moisés, é indubitável, as diversas tribos hebraicas não constituiam uma naçāo, embora reconhecessem que pertenciam tôdas à mesma raça, ou melhor, a uma só etnia. A obra do grande chefe parece ter sido, antes de tudo, uma obra política: a criaçāo de Israel pela fundaçāo de uma religiāo nacional: Yahvé seria o Deus de Israel, e Israel seria o povo de Yahvé!

Tal foi, provàvelmente, o pensamento que resultou de suas meditações, no deserto, diante da fraqueza de seus irmāos e das suas próprias lutas e mútuas perseguições. Antes, aliás, se dermos crédito ao Êxodo, já do "Egito" fugira Moisés para Madian. e ai se casara com a filha de um sacerdote.

Outros povos semitas das vizinhanças possuiam religiões nacionais; entre os moabitas Kemoch era o chefe e a alma da nação, e entre os assírios Achchur desempenhava idêntico papel. A religiāo criada por Moisés não devia, pois, diferir muito de suas congêneres.

Mas como e de onde surgira para Moisés êste deus Yahvé? Ao que se pode depreender, nāo só era, nessa época, o elohim protetor dos quenianos, como também já o era de algumas dentre as tribos hebréias, possivelmente da própria tribo a que pertenciam antepassados do grande chefe. Jetro ou Hobab, sogro de Moisés, pertencia à tribo dos quenianos, e êstes cultuavam Yahvé desde época remotíssima. 
Yahvé era a divindade do Sinai, ou do Horeb, divindade poderosa e feroz, que vivia em permanente contato com certos fenômenos naturais, como o fogo, o relâmpago, o trovāo, a tempestade, o tremor de terra, certamente porque uma dessas montanhas santas era um vulcão em franca atividade. Por isto mesmo, como se lê na Biblia, o terrivel nume aparecia, à noite, aos israelitas, no deserto, como uma sarça ardente, e como uma densa coluna de fumo, à claridade diurna.

Estes ligeiros dados parecem-nos suficientes para provar que, apesar das afirmações do Antigo Testamento, a divindade do Sinai, ou do Horeb, já era talvez conhecida desde tempos imemoriais. Sendo originàriamente, como dissemos, o elohim protetor dos quenianos, êste fato, de algum modo, explica a inteira ignorância dos hebreus, quanto à verdadeira significação de seu nome. Mesmo a pronuncia do vocábulo Yahvé, entre os israclitas, nāo é certa $e$ indiscutivel. Cumpre notar, entretanto, que êles jàmais pronunciaram Jeová!

Adolfo Lods explica a interessante origem desta estultícia, tão repetida no Ocidente: "êste nome provém de um êrro grosseiro dos primeiros cristāos hebraizantes, que, no século XIII, leram as consoantes do nome divino $Y h w h$ com as vogais de ădonay (senhor), palavra que os judeus, por uma questāo de respeito, usam na leitura do texto sagrado, o que indicavam, inscrevendo as vogais sob. as consoantes do tetragrama, de conformidade com o seu sistema de notaçāo das variantes: $Y e H_{0} W a H^{\prime \prime}$.

Apesar da existência do "tratado de exclusividade religiosa Yahvé-Israel", não é possivel acreditar que, no cérebro privilegiado de Moisés, existissem verdadeiras noções monoteistas. Yahvé seria o deus da federaçāo hebraica, mas isto nāo significava que as diferentes tribos deixassem, desde logo, de prestar culto às suas divindades particulares, num politeismo, aliás, ainda muito rudimentar, eivado mesmo de fetichismo bárbaro e primitivo. E nāo é de crer que Moisés pusesse em dúvida a existência dessas outras divindades, pois era ainda êste o pensamento que predominava, entre os hebreus, mesmo muito mais tarde. Referindo-se à reforma de Ezequias, diz o redator do livro dos Reis: "Foi êle quem déstruiu os altos lugares, quebrou as estátuas (estelas), destruiu os bosques (achera) e fêz em pedaços a serpente de metal que Moisés tinha fabricado: porque os filhos de Israel até entāo lhe haviam queimado incenso. Davam-lhe o nome de nehustân" (4 Reis, 18,4).

Falou-se, no século passado, da influência de concepções monoteistas, mais ou menos secretas, entre os sacerdotes egipcios, que encorajariam experiências sociais, em larga escala, no estrangeiro, por lhes não ser possivel fazê-las no próprio vale do Nilo... Mas, infelizmente, nāo existem dados objetivos sôbre semelhantes fatos, nem é possivel crer nesta evoluçāo tāo precoce, que seria, sem dú- 
vida alguma, o rasgo mais genial da história da Humanidade. Há textos egípcios e babilônios que demonstram, realmente, o grau de adiantamento de certos sacerdotes; êstes homens já concebiam os diversos deuses como sendo, apenas, nomes especiais aplicados a um ser divino único, e assim os vários apelidos corresponderiam às manifestações diferentes de uma só divindade. Mas eram, afinal, concepções teológico-metafísicas muito confusas e imprecisas, e. por isto mesmo, incapazes ainda de exercer sensivel influência. De resto, tratava-se antes de especulação panteista, que de verdadeiro pensamento monoteista.

É bem verdade que já houvera, no Egito, um fenômeno social curiosissimo: a revoluçāo chefiada pelo faraó Amenofis IV - Ikhunatom. A côrte desprezou Tebas, indo residir em uma nova capital, que se chamou Ikhutatom (Tell-el-Amarna). A crise politica anti-clerical agigantou-se. Foi imenso o esfôrço dos nobres para se libertarem do dominio, cada vez mais absorvente, dos padres tebanos.

Fala-se, por isto, num periodo de reis heréticos, e até em tentativa oficial de monoteismo. Na realidade esta situaçāo perdurou, apenàs, durante os governos de Amenofis IV (1380-1362), Saakara, Tutankhamom (1362-1350) e Ay (1350-1345).

$O$ que se pretendia, entretanto, era romper com a velha tradiçāo, para poder impor aos povos conquistados uma nova divindade solar imperial. Tratava-se, pois, nāo pròpriamente de um monoteismo, como se tem repetido, mas de uma nova forma de politeismo - um politeismo monárquico, no qual, a divindade superior, Atom, exerceria poderes, não só no Egito, mas na Ásia e no Sudīo. Foi, realmente, uma admirável tentativa político-religiosa para ligar povos de raças e religiões diversas, mas que nāo chegou a sustentar-se durante meio século.

A reforma de Moisés, procurando, apenas, a aproximaçāo de tribos da mesma etnia, mostrava-se incomparàvelmente mais modesta. Diz, com muita razäo, Jules Soury: "Yahvé, a princípio, era uma divindade inteiramente local. Para os antigos hebreus, nāo sòmente Yahvé era deus apenas para Israel, mas nāo estava, de fato, presente, e năo via e nāo escutava a nāo ser no país de seu povo; além dos limites do território, que conquistara e legara a Israel, já nāo era Yahvé quem rénava, mas outros deuses, como êle, igualmente donos e senhores de seus dominios. Pode-se mesmo acrescentar que Yahvé, tal como um antigo fetiche, talvez sob a forma de um aerólito, habitava especialmente a Arca e nela residia; assim havia caminhado em meio dos seus, no deserto; mais de uma vez, a simples presença da Arca, no campo de batalha, havia decidido a vitória. Não se poderá duvidar de que, para Daví e seus contemporâneos, a Arca era o habitáculo de Yahvé. Esta casa ambulante do deus era uma coisa temivel, sinistra, pouco 
segura mesmo para os verdadeiros crentes, diante da qual todos tremiam, israelitas e ifilisteus".

Em 1907, Daniel Völter pretendeu demonstrar que todo o yahvismo nāo passava de uma transposiçāo da mitologia egípcia: Yahvé correspondia a Chepera, o deus sol; a arca era o féretro de Osiris; Moisés seria Thot, o deus da lua nova, legislador, árbitro e grande mago... Felizmente, êsses devaneios já passaram da moda.

A realidade é que a célebre arca encerrava um fetiche, provàvelmente um bloco de pedra do Sinai, testemunha, talvez, da aliança realizada por Moisés. Mas, para a rude mentalidade dêsses pastores, o que os acompanhava, no deserto, dentro do cofre inviolável, era o próprio Yahvé!...

$O$ verdadeiro monoteismo - o monoteismo moral - só surgiu, entre os israelitas, com os profetas dos séculos oitavo e sétimo. Moisés, quando muito, pode ter tentado criar uma singular monolatria. Mas, nem isto conseguiu.

Já acima falámos da reforma de Ezequias. Pois bem, a reforma de Josias, realizada mais tarde, provàvelmente em $622 / 621$, mostra-nos qual ainda era, nessa época, a situaçāo religiosa de Israel, como, aliás, se pode verificar no livro dos Reis (IV, 23, 4 e seg.).

Josias fêz desaparecer do templo de Jerusalém nāo só os objetos sagrados, realmente estrangeiros, como os altares das divindades celestes: o sol, a lua, os doze signos, "e tôda a milícia do céu", elementos desde longa data entronizados em todos os santuários de Yahvé. Retirou, também, do recinto sagrado, uma achera, e acabou com a casa reservada às prostitutas do templo. Extinguiu todos os altos-lugares de Judá, conservando, apenas, o santuário de Jerusalém. Destruiu ou profanou todos os emblemas pagãos (embora muitos fôssem puramente israelitas) nāo só de Jerusalém, como das vizinhanças. Acabou com o santuário dos sátiros, que ficava perto de uma das portas da cidade. Destruiu o altar onde se queimavam crianças, no vale de Ennom; queimou o carro e os cavalos consagrados ao sol, e extinguiu os altos-lugares dedicados por Salomão a diversas divindades estrangeiras, como Astaroth, Camos e Melcom, no monte das Oliveiras.

Nāo é possivel, portanto, aceitar nem mesmo a existência de uma verdadeira monolatria, entre os israelitas, antes dos profetas. Se Moisés tentou, de fato, institui-la, havemos de convir, como já dissemos, que nāo foi muito feliz em sua iniciativa. 
Passaremos, agora, em sumária revista, o problema relativo ao Decálogo. Sem dúvida, os chamados "Mandamentos da Lei de Deus" podiam ter sido inspirados pelos preceitos que, pouco a pouco, foram serido instituidos pelos sacerdotes tebanos, através de observações seculares.

Aliás, nāo nos parece difícil apresentar bases para esta suposição. Basta refletir ligeiramente sôbre alguns documentos egípcios, diante dos quais a antiguidade da Biblia é, por assim dizer, quase insignificante.

Tomaremos, como exemplo, o resumo de uma confissāo negativa, segundo o capítulo CXXV do "Livro dos Mortos". Comparecendo diante do divino tribunal, que o vai julgar, afirmava um defunto, há cêrca de quatro mil anos: - "Nāo pratiquei nenhum mal. Não cometi violência, nāo roubei, não matei homem traiçoeiramente. Nāo diminui as oferendas (dos deuses), nāo menti, nāo fiz chorar, nāo fui impuro, nāo matei os animais sagrados. Nāo danifiquei as terras cultivadas, nāo fui caluniador, nāo fui colérico, nāo fui adúltero. Nāo recusei palavras de verdade, nāo cometi malefícios contra o rei, nem contra meu pai. Nấo sujei a água, nāo fiz o senhor castigar o escravo, nāo jurei (falso), nāo estortei o fiel da balança, nāo tirei o leite da bôca das crianças. Nāo apanhei com a rede os pássaros dos deuses, nāo repeli a água em sua sazão, não obstruí nẹnhum rêgo em sua passagem, năo apaguei o fogo fora do tempo. Não desprezei deưs em meu coração. Eu sou puro, sou puro, sou puro!".

E nítida a superioridade dos "mandamentos" que desta confissāo se podem deduzir, em cotejo com os que são atribuidos a Moisés. Nota-se claramente. entre os egípcios, a existência de principios que condenavam os pecados de crueldade, cólera, luxúria, orgulho, mentira. vale dizer, as faltas que sobretudo amesquinham a dignidade pessoal.

E, realmente, êsse velho egípcio revela-se, pela confissão, talvez muito mais puro, e talvez muito mais educado do que o homem comum do nosso século!

Nas "Máximas" de Ani, célebre escriba, vêm-se muitos dos preceitos fundamentais da elevada moral egipcia cintilar através de exemplos, ao mesmo tempo simples e pitorescos. Diz êle: "Uma mulher, cujo marido está ausente, e que todos os dias te diz: "eu sou bonita", quando nāo há testemunhas... é um grande pecado, digno de morte, quando se líe dá ouvidos..."

Digno de morte seria, por conseguinte, o homem que desse ouvidos à seduçāo, porque cometeria uma deslealdade contra o seu vizinho,

No Decálogo, entretanto, esta regra parece que foi traçada com espirito diverso, muito menos nobre e muito mais grosseiro. a mulher do vizinho é "coisa" que tem dono, e só por isto nāo pode ser usada sem a sua licença. Diz, com efeito, o mandamento: 
"Nāo cobiçarás a casa do teu próxłmo: nāo desejarás a sua mulher, nem o seu servo, nem a sua serva, nem o seu boi, nem o seu jumento, nem coisa alguma que lhe pertença".

Há ainda, no Decálogo, um outro mandamento que proíbe o adultério. Mas a verdade, como lembra Soury, é que, depois dos sacrifícios humanos, a prostituiçāo sagrada era a característica essencial da religiāo primitiva dos beni-israel. Yahvé exigia, de fato, as primícias, inclusive os primogênitos dos homens; lá está no Exodo: "Consagra-me todos os primogênitos que abrem o útero de sua máe entre os filhos de Israel, assim de homens, como de animais, porque todos êles sāo meus" (13,2). As tendas das prostitutas erguiam-se nos "altos-lugares", ao lado da estela de Baal, ou de Yahvé, e do símbolo de Achera, que era uma simples estaca.

Em Jerusalém, no próprio templo de Yahvé, como vimos, adorava-se o símbolo desta deusa e havia celas para as suas "sacerdotisas": "Ele (Josias) demoliu as casas dos sodomitas (quedeschim), que existiam no templo de Yahvé, onde mulheres urdiam as tendas para Achera" (II Reis, 23,7). O Deuteronômio demonstra que as mulheres e os homens, dêsse mister, entregavam o produto de seu "trabalho" ao tesouro do templo de Yahvé, cujas despesas, de resto, deviam ser formidáveis...

Deixando, porém, de parte todos êsses pormenores, o que devemos ter como rigorosamente certo é o seguinte: nenhum elemento do Pentateuco pode ser referido à época mosaica. O Decálogo, na sua forma atual, nāo se poderia destinar às tribos nômades, que Moisés procurava unir e guiar. A sua simples leitura mostra-nos que foi redigido para um povo sedentário, que já possuia cidades muradas, criava bovinos e vivia principalmente da agricultura. Deve, pois, ter aparecido muito mais tarde, provàvelmente no século VII. A propósito, Adolfo Lods diz textualmente o seguinte: "O Primeiro Decálogo, na redaçāo que lhe dá o Deuteronômio $(5,1-21)$, é posterior a 622 , porque apresenta numerosos traços da lingua e das idéias do código deuteronômico. Sob a forma em que é apresentado no Êxodo $(20,2-17)$ ainda é mais tardio, pois contém uma referência à história da criaçāo".

Nos documentos tradicionais, nas antigas versões dos livros, em que figuram, com grandes variações, os têrmos primitivos da aliança de Yahvé com Israel, nāo se encontram, de nenhum modo, as fórmulas sintéticas, que tāo grande importância vieram a ter para a civilizaçāo ocidental, através do cristianismo.

Isto bem se compreende, porque os deveres morais e sociais que os mandamentos estabelecem, nāo podiam ocorrer a criadores errantes de cabras e carneiros. 
Os argumentos acima resumidos negam, pois, inteiramente a Moisés, não só o estabelecimento do monoteismo, entre os hebreus, mas ainda a própria sintese das fórmulas morais, que hoje se encontram no Decálogo.

Procurando fugir a minúcias desnecessárias, lembraremos ainda, entretanto, antes de terminar, diversos fatos secundários, que também demonstram quanto foi destituida de significaçāo a influência egipcia, durante a fase inicial do desenvolvimento de Israel.

Em verdade, nāo se pode negar que o santuário de Serabit el-Hadin, na peninsula do Sinai, prove, de certo modo, a infiltraçāo do culto nilótico entre os pastores da regiāo, pois a deusa semítica, que aí se adorava, tinha, sem dúvida, o aspecto geral de Hathor.

É muito provável, também, que a circuncisāo se tenha introduzido, primitivamente, entre algumas tribos de Israel, por influência africana, porquanto, segundo a versāo yahvista, foi nas fronteiras do Egito, e por um madianita, que, pela primeira vez, se praticou essa pequena operação em um hebreu, aliás, pouco antes do êxodo (Ex. 4, 24-26). De mais a mais, a realidade é que se a circuncisāo se tornou sistemática e obrigatória, entre os israelitas, no tempo de Josué, foi com o fito de livrar o povo de Yahvé do profundo desprêzo que os egipcios mostravam ter pelos incircuncisos.

Quanto ao resto, o exame rigoroso dos fatos prova que a influência do Egito, a princípio, foi nula, ou quase nula.

As idéias dos antigos hebreus sôbre a condiçāo dos mortos, por exemplo, ou sôbre os tabus alimentares e a ausência de imagens da divindade são conceitos de origem autênticamente semítica, como muito bem explica Adolfo Lods.

O culto fetíchico do "bezerro de ouro", em pleno deserto, tal qual hoje se lê no Êxodo, é um pormenor puramente lendário, que, de resto, só foi introduzido no texto primitivo muitíssimo mais tarde, embora ainda com uma ingenuidade irrisória.

Onde, realmente, iriam êsses pobres beduinos encontrar o ouro necessário para fazer o seu idolo? Roubado aos egípcios? Mas, onde achariam o artista que moldasse a estátua, e onde buscariam os recursos para fundir o metal, nessas estepes desoladas?

Os egipcios, no entanto, nāo adoravam estátuas de touros; cultuavam os próprios bois, vivos, de carne e osso...

Percebe-se hoje que a tardia introduçāo da lenda do bezerro de ouro, no texto do Exodo, teve por objetivo legitimar o culto do touro, dando-lhe uma origem remota, ligando-o à própria época mosaica. Este culto, os israelitas o haviam copiado, nāo dos egípcios, mas dos cananeus.

Também a divisão do santuário israelita, em "lugar santo" e "lugar santíssimo", nāo decorreu do exemplo egípcio. Ao que parece, esta divisāo só se firmou muito tarde, pois, em Silo, o jovem 
Samuel ainda dormia na própria câmara em que se guardava a Arca da Aliança.

Em resumo, portanto, pode-se agora afirmar, que a propalada influência do Egito sôbre Israel foi muito tardia, e provàvelmente só se positivou por intermédio dos cananeus, que, como se sabe, durante largos anos, foram vassalos dos faraós, conseguindo, assim, assimilar, de algum modo, a cultura e as devoções de seus senhores. A rigor, só mesmo na época de Salomāo, e posteriormente, é que se observam, entre os hebreus, fatos indiscutiveis, que demonstram a influência da admirável civilizaçāo nilótica.

JOÃO FRANCISCO DE SOUZA. 